\title{
An easy to control all-metal in-line-series ohmic RF MEMS switch
}

\author{
M. Spasos ${ }^{1,2}$, N. Charalampidis ${ }^{1}$, K. Tsiakmakis ${ }^{1}$, R. Nilavalan ${ }^{2}$ \\ (1) Department of Electronics, \\ Alexander Technological Educational Institute \\ Sindos, Thessaloniki, GREECE \\ spasos@el.teithe.gr \\ (2) Department of Electronic and Computer Engineering \\ Brunel University \\ Uxbridge, London, UNITED KINGDOM
}

\begin{abstract}
The analysis, design and simulation of a novel easy to control all-metal in-line-series ohmic RF MEMS switch is presented, for applications where the operating frequency ranges from DC to $4 \mathrm{GHz}$. The proposed switch, due to its unique shape and size, assures high isolation and great linearity fulfilling the necessary requirements as concerns loss, power handling and power consumption. Simplicity has been set as the key success factor implying robustness and high fabrication yield. On the other hand, the specially designed cantilever-shape (hammerhead) allows distributed actuation force ensuring high controllability as well as reliability making the presented RF MEMS switch one of its kind.
\end{abstract}

Index Terms: Ohmic RF MEMS switch, simplicity, controllability, reliability

\section{Introduction}

The exponential growth of wireless communications requires more sophisticated system design to achieve higher integration, power saving and robustness. System design concentrates in developing high frequency, low scale configurations to follow the trends of the market for smaller, technologically more advanced applications. In the same manner, technological advances in radio-frequency (RF) front-ends, such as reconfigurable antennas, tunable filters, phase shifters, switching networks etc require state of the art switches to allow operation in cognitive wireless networks [1].

Ohmic RF MEMS switches utilize physical contact of metal with low contact resistance to achieve low insertion loss when actuated. Their isolation is defined by the coupling capacitance of the electrodes when the switch is open. Thus, the ohmic MEMS switches are used where low loss devices are necessary, capable of reliably handling a few watts of RF power and operate in the frequency band from $\mathrm{DC}$ to $10 \mathrm{GHz}[2-3]$.

The design approach followed in this work was mainly towards the simplicity, the reliability, the controllability and the power handling of the RF MEMS switch, while great effort has been paid in analyzing all possible failure mechanisms too. The investigation of the proposed design has been carried out using Coventorware 2008 software package [4], for electromechanical and electromagnetic analysis.

\section{Design considerations and reliability issues}

The materials, the shape, the dimensions of the cantilever, the contact area, the gaps between the contacts, the gap between the cantilever and the electrode, the dimensions and distribution of electrodes have been chosen such to fulfill the constraints and reliability issues. Details of the electrode area and the contact areas are shown in Fig. 1, while the complete design of the proposed all metal in line series ohmic RF MEMS switch incorporating the perforated cantilever (expanded 10 times in the $\mathrm{z}$ axis), is shown in Fig. 2. 


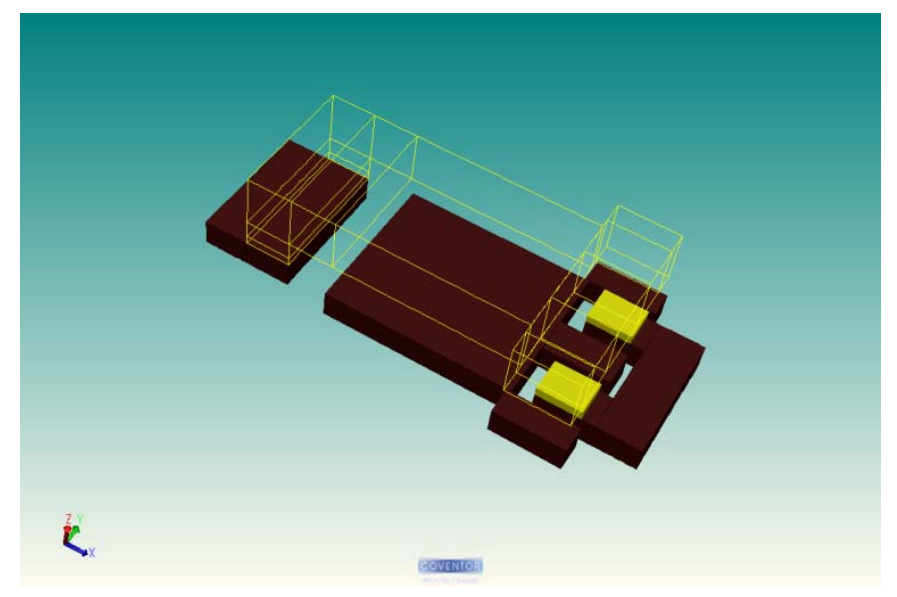

Fig. 1 The electrode area

As far as the dimensions and the shape of the proposed switch are concerned several constraints have been taken into account during the design process. First of all the actuation voltage should be kept within reasonable range thus the size of the cantilever, width, height and length, should be accurately considered so as to simultaneously fulfill other performance parameters such as the restoring force and the balanced operation within a hermetic package. The two contact areas form two parallel capacitors thus, although the contact area must be relatively big to ensure low resistance and power handling it should simultaneously be relatively small to ensure high isolation. Large nominal contact areas do not directly lower the contact resistance if the contact force is not increased. However, they provide a better heat distribution from the effective contact spots heated by the dissipated power of the signal current flowing over the contact interface and nonlinearities are avoided [5-6]. On top of that the hardness of the contacts should be considered for a minimum of surface adhesion wear. Additionally, the distance in between the contacts in the OFF state must be above a minimum height to ensure proper isolation. As regards the gap between cantilever and electrode it must be kept above a minimum height to avoid self actuation in case of a high in amplitude RF signal. Moreover, the dimensions and the shape should be chosen such to utilize the fringing field's properties, achieving higher switching speed, better controllability and limiting bouncing phenomena. Finally, using a non-uniform shaped cantilever (hammerhead) and a sophisticated contributed electrode area could keep the actuation voltage low while simultaneously improve the switching control.

As regards the fabrication process perforations in the cantilever have been adopted to make the sacrificial layer removal easier and more efficient. These holes also reduce the stiffness of the cantilever as well as the squeeze film damping increasing switching speed. Finally, they lower the beam mass resulting to a higher mechanical resonant frequency. A complete list of the switch's dimensions is presented in Table I.

On the other hand, the material chosen to design the proposed switch was gold $(\mathrm{Au})$ due to its exceptional electrical, mechanical and chemical characteristics [7]. To avoid stiction phenomena high restoring force is necessary. Restoring force mainly depends on the stiffness of the cantilever which is determined by the width, the thickness and the Young Modulus of the material and affects significantly the magnitude of the pull-down voltage of the cantilever [8].

The mechanical spring constant $\mathrm{k}$ of the cantilever with distributed load in a part of the cantilever is given by [2]:

$$
k=2 E w\left(\frac{t}{l}\right)^{3} \cdot \frac{1-\frac{x}{l}}{4-3\left(\frac{x}{l}\right)^{3}+\left(\frac{x}{l}\right)^{4}}=15.6 \mathrm{~N} / \mathrm{m}
$$

where: $\mathrm{E}=57 \mathrm{GPa}$, the Young modulus of $\mathrm{Au}$ that as used in Coventorware software package $\mathrm{w}=150 \mu \mathrm{m}$, the width of the first part of the cantilever

$\mathrm{t}=5 \mu \mathrm{m}$, the thickness of the cantilever

$\mathrm{l}=350 \mu \mathrm{m}$, the length of the cantilever

$\mathrm{x}=70 \mu \mathrm{m}$, the distance from the anchor to the electrode

The pull-down voltage, where the cantilever travels the $1 / 3$ of the distance to electrode is 
calculated by:

$$
V_{p}=\sqrt{\frac{8 k g_{0}^{3}}{27 e_{0} A}}=18.7 \mathrm{~V}
$$

where: $A=4 \times 10^{-8} \mathrm{~m}^{2}$, the area of the electrode $\mathrm{e}_{0}=8.86 \times 10^{-12} \mathrm{~F} / \mathrm{m}$, the permittivity of free space $\mathrm{g}_{0}=3 \mu \mathrm{m}$, the gap between cantilever and electrode $\mathrm{k}=15.6 \mathrm{~N} / \mathrm{m}$, the spring constant of the cantilever

The electrostatic force $\mathrm{F}_{\mathrm{e}(\operatorname{arc})}$, applied for arc-shape deformation of the cantilever, is calculated as:

$$
F_{e(\operatorname{arc})}=\frac{e_{0} \cdot A \cdot V_{p}^{2}}{2 g_{\operatorname{arc}}^{2}}=16.85 \mu \mathrm{N}
$$

where: $\mathrm{g}_{\mathrm{arc}}=2 \mu \mathrm{m}$, the remaining gap between cantilever and the middle of the electrode,

Restoring force can also be increased by making use of the s-shaped deformation of the cantilever. Initially by applying a pull-down voltage $V p$, the edge of the upper contact area can be brought down into contact with the bottom contact area. However, in this case, the contact area is small; the resulted contact material deformation is also too small to generate a low contact resistance and the restoring force of the cantilever is not enough to prevent the switch from stiction. The solution is to increase the actuation voltage well above the pull-down voltage $V p$, the electrostatic force $F_{e}$ is increased, further bending the cantilever and reducing the contact resistance and increasing the restoring force.

The electrostatic force $\mathrm{F}_{\mathrm{e}(\mathrm{s})}$, applied for full contact under S-shape deformation of the cantilever, is calculated as:

$$
F_{e(\operatorname{smin})}=\frac{e_{0} \cdot A \cdot V_{s}^{2}}{2 g_{s}^{2}}=174 \mu N
$$

where: $g_{s}=1.34 \mu \mathrm{m}$, the remaining gap between cantilever and the middle of the electrode $\mathrm{V}_{\mathrm{s}}=42 \mathrm{~V}$, the actuation voltage for full contact ( $\mathrm{S}$-shape)

Apart from the contact force and the effective contact area, contact resistance also depends on many other parameters. Contact materials, metal deposition process, surface roughness, contact cleaning procedure, surface contamination, atmospheric environment and switching history are some of the most important. Gold comprises the most suitable material for the switch due to its high conductivity $\left(0.409 \cdot 10^{8} / \Omega \cdot \mathrm{m}\right)$ which implies less skin depth, it is chemically stable material since it does not form oxides or sulfides, keeping surface contamination low thus ensures longevity and last but not least it has been shown that $\mathrm{Au}-\mathrm{Au}$ ohmic contacts can reach $10^{8}$ cycles of lifetime without significantly deteriorate their performance, among them contact resistance [9]. Surface roughness and contact cleaning procedure directly affect the contact resistance and special care should be taken during the fabrication process. Nevertheless, due to the additional actuation voltage applied to the electrode (beyond $V p$ ), friction is created between the contacts which may also help to mechanically wipe the surfaces maintaining low contact resistance [9-10]. 


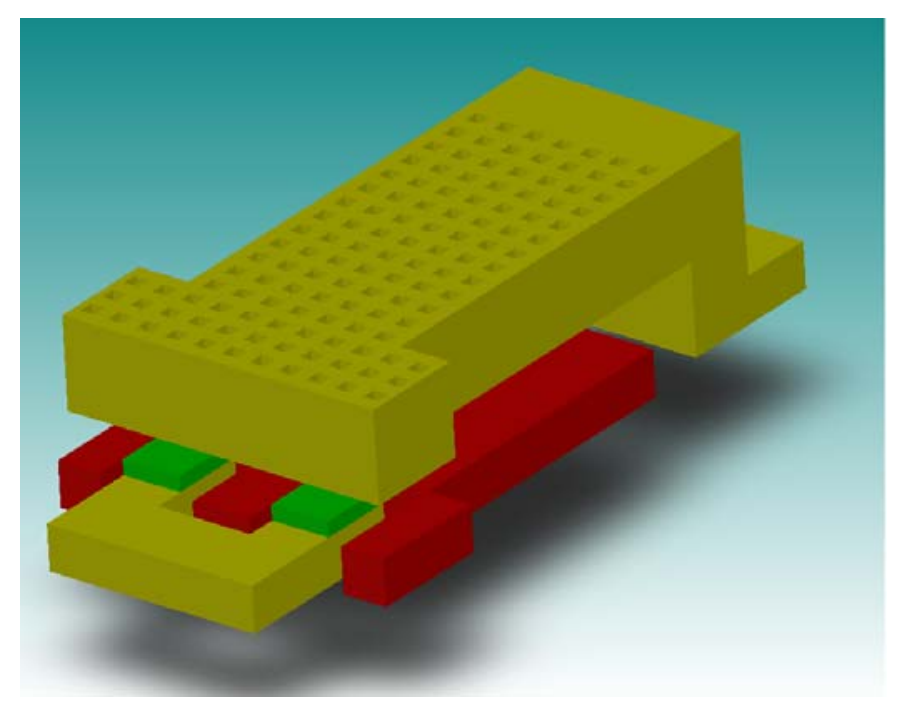

Fig. 2 The proposed Ohmic RF MEMS switch

\section{Controlling the switch}

Under nominal fast pulse switching conditions, when contact is achieved, the contact force is very high due to the high impact velocity of the collapsed cantilever. Instantly, the conductance becomes very high but unstable, due to the bouncing of the cantilever which follows the first contact. Consequently, additional time is necessary for a stable contact force and thereof a stable conductance to be achieved. This bouncing behavior increases the effective closing time of the switch.

Instead of using a continuous step command or a series of square waves to control the electrode, the proposed command uses a series of pulse trains with precisely calculated applied voltages and time intervals, schematically shown in Fig. 3 [11].

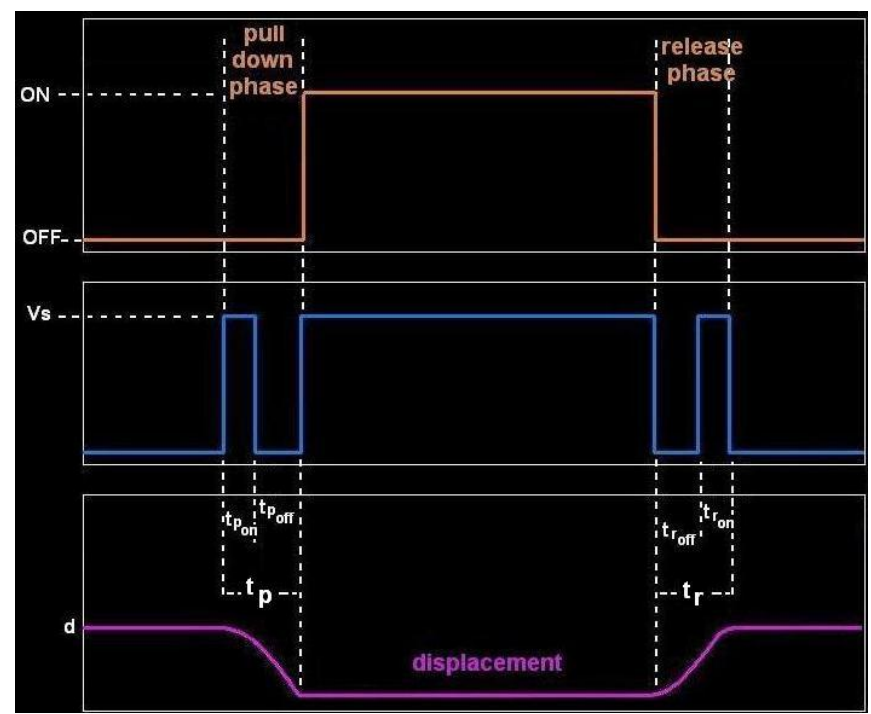

Fig. 3 Phases of the tailored actuation pulse

The entire operation can be classified into two phases, the "pull-down" phase and the "release phase". The pull-down phase mainly concerns the actuation of a contact switch from its original null position to the final contact position. A proper design must achieve a rapid and low impact response (ideally zero velocity) at the time of contact and a fast settling once the switch is released from its contact position back to the null position. Special effort must be paid in the release phase due to the fact that considerable residual vibration at the null position could be 
generated before settling, reducing the switching rate during a repeating operation and producing undesirable noise, as the isolation of the switch is unstable, during hot switching operation.

\section{Simulation results}

The simulation results have been extracted under the following environmental conditions: Temperature: $293^{\circ} \mathrm{K}\left(20^{\circ} \mathrm{C}\right)$, Pressure: $730 \mathrm{mTorr}(1 \mathrm{Atm})$ and Gas type: Nitrogen. In order to create reliable operating conditions various damping effects (material, gas) have been taken into account in the dynamic simulations. Thus, the switch designed initially in Designer module of Coventorware and then analyzed in Analyzer module, using a Finite Element Analysis (FEM) code, to compute the resonance frequency, Rayleigh's modal damping coefficients $\alpha$ and $\beta$, the inductance, the resistance and the spring stiffness.

The final evaluation of the proposed ohmic RF MEMS switch has been carried in the reduced order modeling environment of Architect module of Coventorware. Then, in Saber Sketch schematic editor of the same package, the switch has been connected to arbitrary power sources to extract its performance specifications.

Under fast pulse implementation, undesirable conditions such as high impact forces and bouncing phenomena appeared to the switch, which render its operation problematic, as shown in Fig. 4. The actuation pulse was set to $42 \mathrm{~V}$ so as a full contact to be achieved. The switching time was some $19.6 \mu \mathrm{s}$. Nevertheless, the impact force is very high, almost $1 \mathrm{mN}$. This instantaneous high impact force, after several cycles of operation, may induce local hardening or pitting of the contact material and dislocations in the metal structure, affecting longevity. Additionally, the displacement graph indicates dramatic bouncing phenomena after the release phase (the actuation pulse stops). The cantilever is released but due to its restoring force it bounces back and touches the contact again. It can be graphically calculated that the front end of the cantilever rises up to some $3.2 \mu \mathrm{m}$ above its null position and bounces back to the $-2 \mu \mathrm{m}$, its close position, while the bouncing phenomena carry on for long time after the actuation pulse stops.

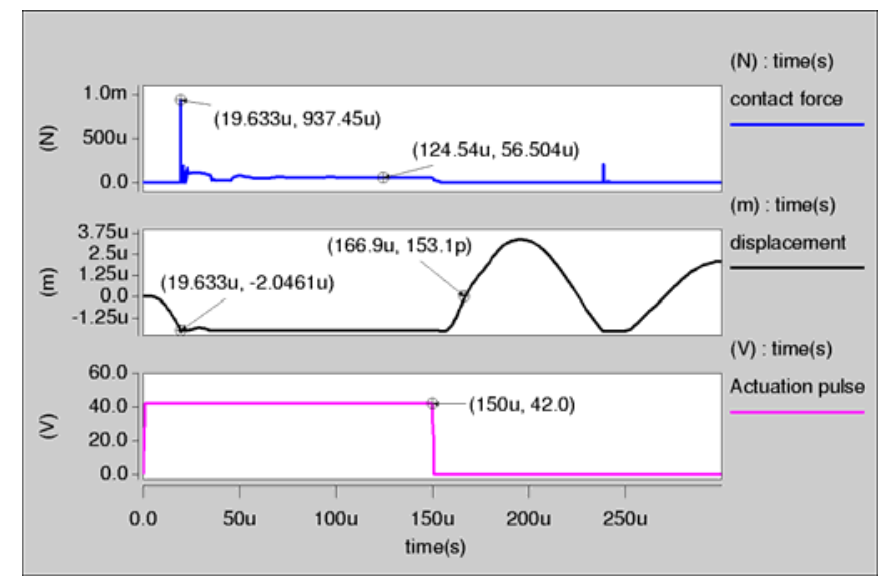

Fig. 4 Switch's behavior under fast pulse

Thus a tailored actuation pulse was implemented to control the switch and its electromechanical characteristics have been obtained via transient analysis.

The tailored actuation pulse is illustrated in Fig. 6 and divides a switching cycle into four sections, described below:

1. The pull-down section 0 to $26 \mu$ s which is modified to minimize the velocity and consequently the impact force of the switch.

2. The ON state section of the switch, between 26 and $150 \mu \mathrm{s}$.

3. The release time section of the switch 150 to $176 \mu$ s which is set accordingly to minimize the residual vibration at the null position before settling.

4. The OFF state section of the switch between 176 and $500 \mu \mathrm{s}$.

The full properties of the tailored actuation pulse are shown in Table II.

The results of the tailored actuation pulse as concerns displacement, conductance, contact area and contact force are illustrated in Fig. 5. By applying the tailored actuation pulse, high impact force and bouncing phenomena have been almost eliminated. Under these conditions: 
- The switching time is $26 \mu$ s for the ON state transition, $6 \mu$ s slower compared to the sharppulse implementation. The switching time for the OFF state transition remains at $18 \mu$ s but the maximum variation of the cantilever over the null position during the settling time is reduced from $3.2 \mu \mathrm{m}$ to $67 \mathrm{~nm}$. The impact velocity is reduced from 23 to $5.4 \mathrm{~cm} / \mathrm{sec}$ resulting degradation in the initial impact force from 917 to $176 \mu \mathrm{N}$.

- The conductance under stable conditions is $2.6 \mathrm{~S}$ which corresponds to a resistance of $0.38 \Omega$, and the settling time for that is about $35 \mu$ s.

- The contact area graph, shown in the same figure, indicates that full contact $2 \mathrm{~nm}^{2}$ is obtained at about $35 \mu$ s.

- The stable value of the contact force is $56.5 \mu \mathrm{N}$ although that is after a settling time of $35 \mu \mathrm{s}$.

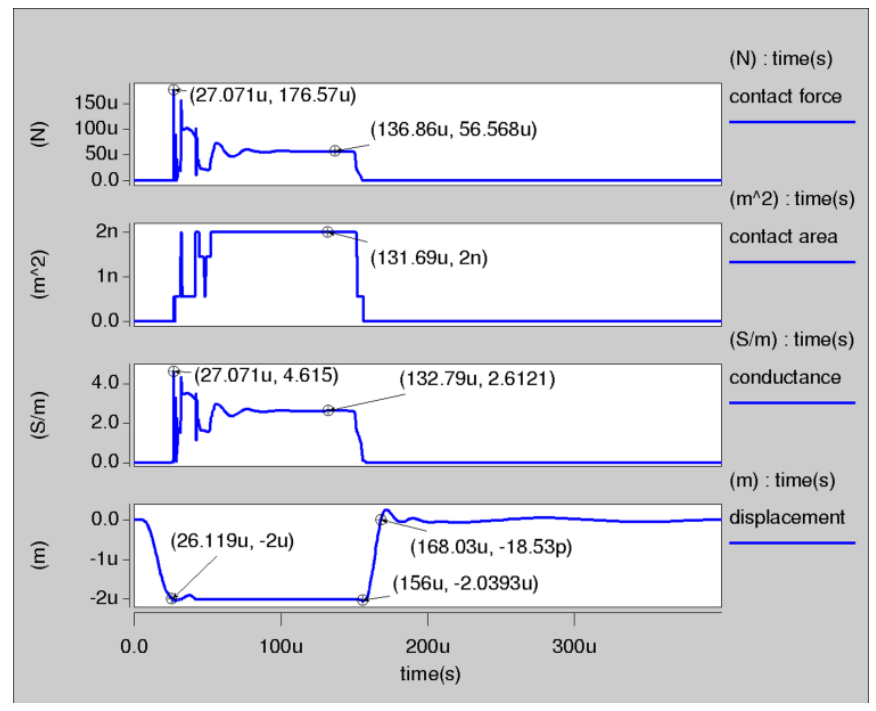

Fig. 5 Switch's behavior under tailored actuation pulse

In RF MEMS it is often supposed that there is no current consumption as there isn't any ohmic contact between the cantilever and the electrode. Nevertheless this quick movement of the cantilever during the pull-down and release phases changes rapidly the capacitance and creates a transient phenomenon. Thus for this small time periods there is an instantaneous current request which can be as high as $4.57 \mu \mathrm{A}$, corresponding to an instantaneous power demand of $184.42 \mu \mathrm{W}$, as illustrated in Fig. 6.

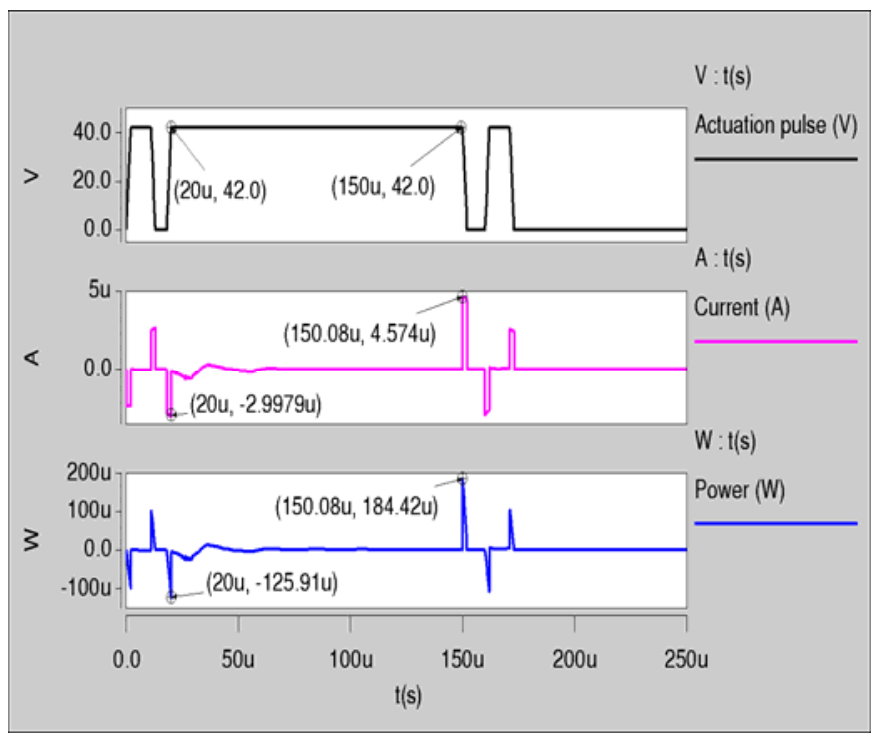

Fig. 6 Tailored actuation pulse and power source demands during switching operation 
Last but not least, Fig. 7 presents the damping influence of the perforated gold cantilever under the pre-mentioned gas conditions. To obtain a realistic approach of the non-uniform squeeze damping effect, the simulation took into account the computed in Analyzer Module Rayleigh's modal damping coefficients.

Damping force may significantly affect the dynamics of the switch, since it is dissipative and is as much as $8.3 \%$ of the electrostatic force for an actuation voltage of about 1.1 times the threshold voltage. Besides, it can be seen that the damping force reaches its maximum just before the switch makes its initial contact. At this moment the gap attains its minimum value and the speed its maximum. The negative value denotes the consumption of the electrostatic force and becomes positive when the switch starts bouncing.

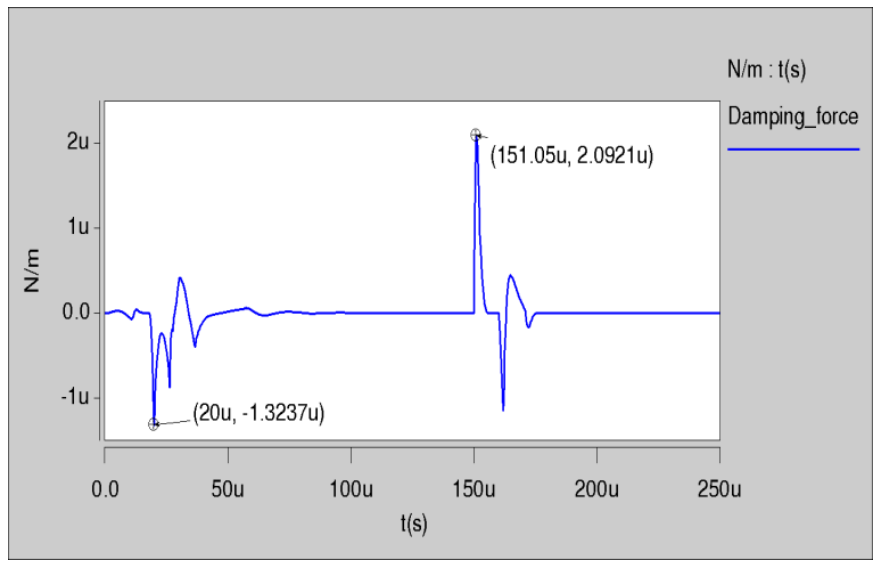

Fig. 7 Damping force graph during switching operation

\section{A. Hot switching mode of operation}

The conductance, the contact area and the contact force have been investigated when a $2 \mathrm{GHz}$ $1 \mathrm{~V} \mathrm{AC}$ input signal has been applied and are shown in the Fig. 8 below. Comparing the results with those without input signal (Fig. 5), as concerns their maximum values, it is clear that there is an increment due to added amplitude of the RF signal.

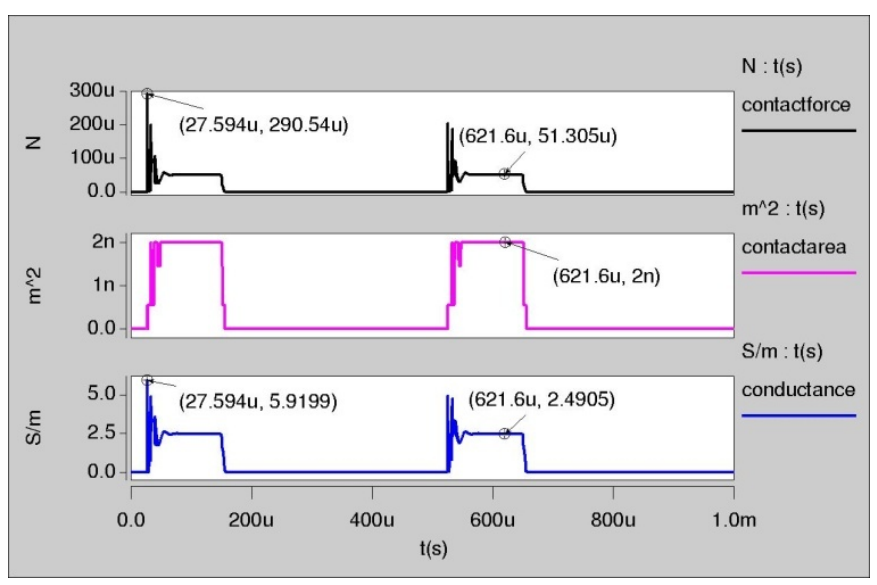

Fig. 8 Conductance, contact area and contact force when 1V RF input signal is applied

Figure 9 shows the expanded view of the RF output during the transition time, when an RF signal with amplitude $1 \mathrm{~V}$ and frequency of $2 \mathrm{GHz}$ is applied in combination with tailored actuation pulse. The produced graph is indicative of the influence of the capacitor which is created between the cantilever and the contact area. 


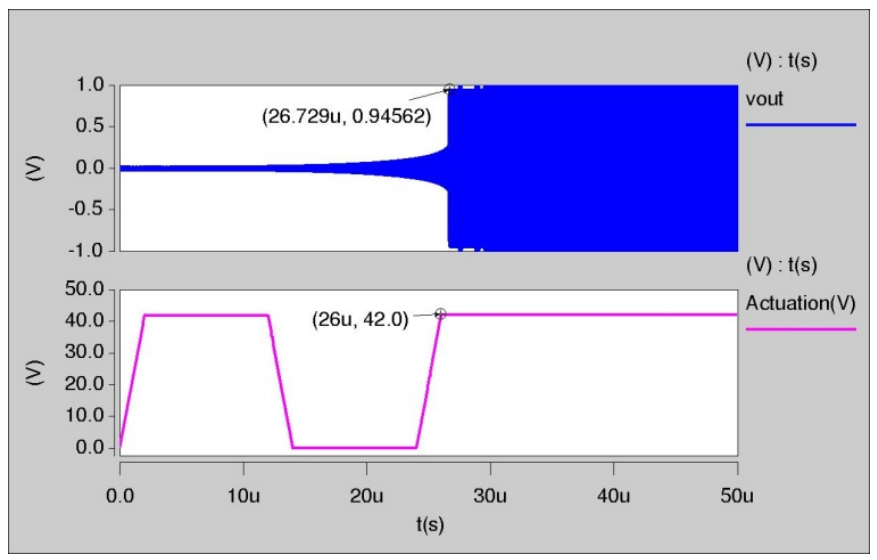

Fig. 9 Detailed switch behavior during transition time

Figure 10 presents the results of the FFT analysis of the output when the above input signal is applied at three discrete periods of time. The sampling rate is defined by the expression:

$$
S_{R}=\frac{N_{\text {points }}}{t_{\text {start }}-t_{\text {stop }}}=\frac{2048}{2 \mu s-2.2 \mu \mathrm{s}}=10.24 \mathrm{GHz}
$$

where: Npoints, specifies the number of data points to be written to the output waveform, $t_{\text {start }}$, the beginning of the time segment to be analyzed

$t_{\text {stop}}$, the ending of the time segment to be analyzed

For the time period 20 to $20.2 \mu$ s the switch is on the OFF state and the $\mathrm{S} / \mathrm{N}$ ratio is $71.9 \mathrm{~dB}$. For the time period 26.5 to $26.7 \mu$ s, during the transition time of the switch, the $\mathrm{S} / \mathrm{N}$ ratio deteriorates to $64.9 \mathrm{~dB}$. For the time period 40 to $40.2 \mu \mathrm{s}$ the switch is in the stable ON state and the $\mathrm{S} / \mathrm{N}$ ratio reaches $78.9 \mathrm{~dB}$.

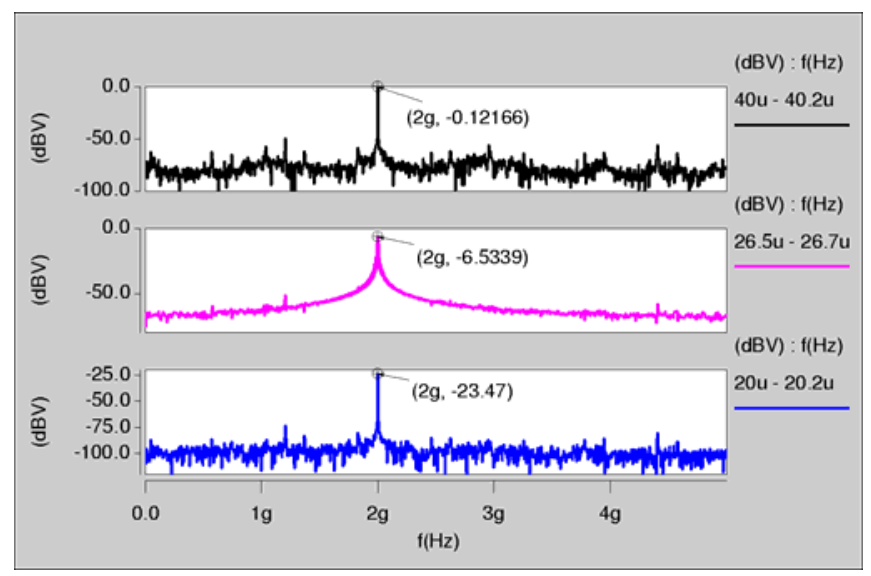

Fig. 10 FFT analysis of the output signal at three discrete periods of time

According to the above analysis and simulation results of the switch under hot mode operation it can be concluded that it works well enough with $1 \mathrm{~V}$ of input RF signal and the S/N ratio is reserved in a very satisfactory level even during the transition time.

\section{B. Electromagnetic analysis}

A full electromagnetic wave analysis has been carried out to further investigate the Sparameters of the switch. Figure 11 presents the return loss and the insertion loss graphs in the frequency range 2 to $10 \mathrm{GHz}$, when the switch is in the ON state. The results of the simulation are very promising as the values of the Insertion and Return Loss are $-0.022 \mathrm{~dB}$ and $-55.3 \mathrm{~dB}$, respectively, at $4 \mathrm{GHz}$. 


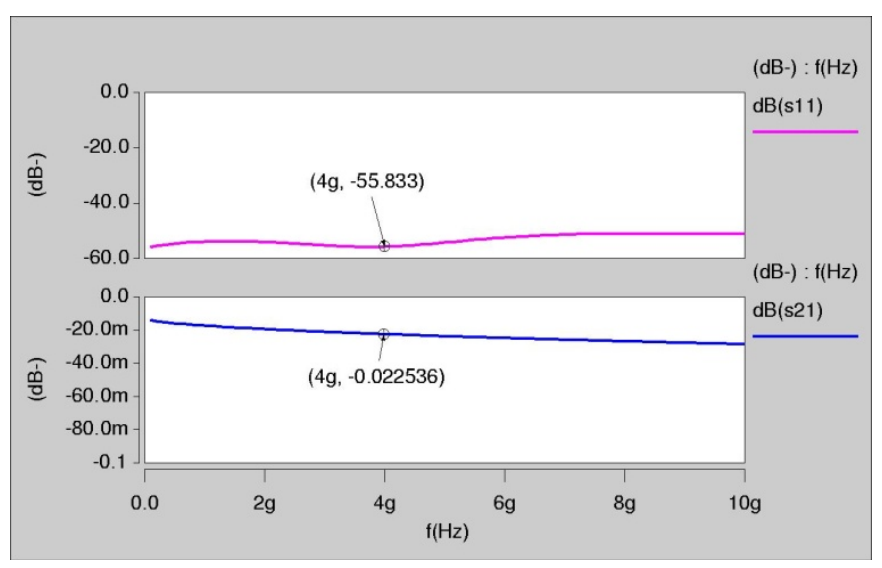

Fig. 11 Insertion and Return loss of the proposed switch in the ON state

The same parameters investigated in the OFF state of the switch, presenting significant results. The Return loss was $-0.045 \mathrm{~dB}$ and the Isolation $-20.63 \mathrm{~dB}$ at $4 \mathrm{GHz}$. The results are illustrated in Fig. 12.

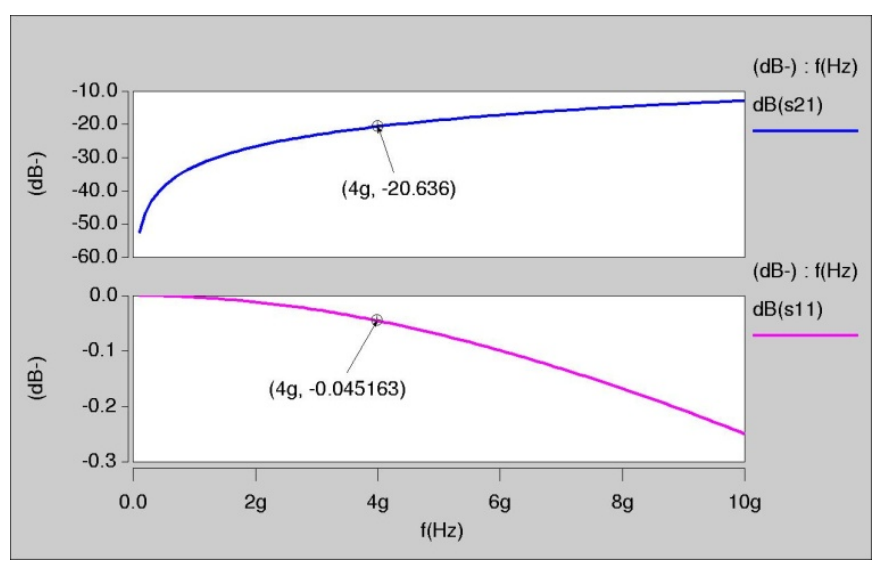

Fig. 12 Isolation and Return loss of the proposed switch in the OFF state

Finally the evolution of the S-parameters $\left(\mathrm{S}_{11}, \mathrm{~S}_{21}\right)$ has been investigated during the transition from the OFF to the ON state, under a DC voltage sweep analysis and is presented in Fig. 13. The frequency of the RF input signal was $4 \mathrm{GHz}$ and the amplitude $1 \mathrm{~V}$. Therefore, as it is observed, the final transition takes place between $15-20 \mathrm{~V}$ indicating the voltage actuation area that has to be avoided in order to ensure reliable and predictable operation of the switch.

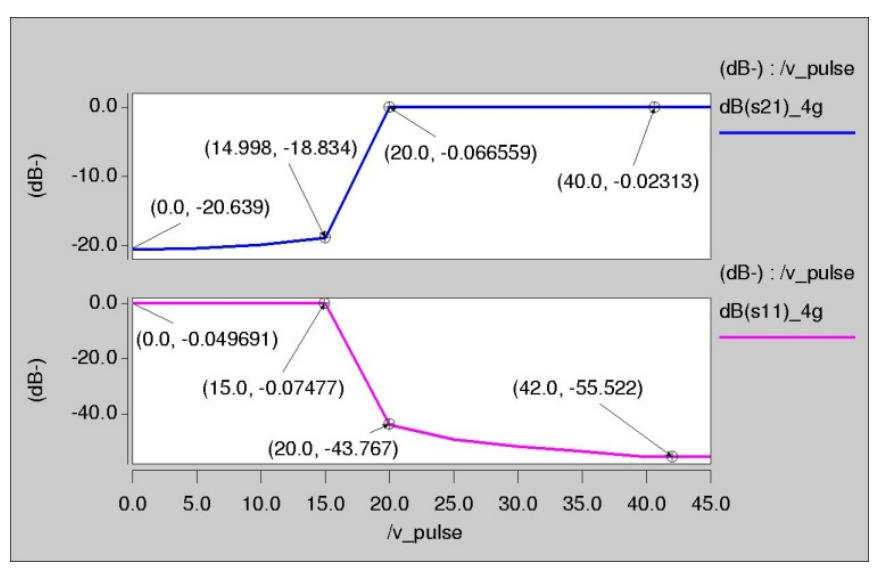

Fig. 13 Evolution of the S-parameters in $4 \mathrm{GHz}$ 
A summary of the simulated electromechanical and electromagnetic results of the proposed all metal in line series ohmic RF MEMS Switch is presented in Table I.

TABLE I

DIMENSIONS AND SIMULATION RESULTS OF THE PROPOSED SWITCH

\begin{tabular}{|c|c|c|c|}
\hline Parameter & Value & Parameter & Value \\
\hline $\begin{array}{l}\text { Length } \\
\text { (cantilever) }\end{array}$ & $350 \mu \mathrm{m}$ & $\begin{array}{l}\text { Actuation(Vp) } \\
\text { Full contact(Vs) }\end{array}$ & $\begin{array}{l}19 \mathrm{~V} \\
42 \mathrm{~V}\end{array}$ \\
\hline Width & $\begin{array}{l}150 \mu \mathrm{m}- \\
220 \mu \mathrm{m}\end{array}$ & $\begin{array}{l}\text { Switching } \\
\text { time }\end{array}$ & $\begin{array}{l}26 \mu \mathrm{S}-\mathrm{ON} \\
18 \mu \mathrm{S} \text { OFF }\end{array}$ \\
\hline $\begin{array}{l}\text { Height from } \\
\text { electrode }\end{array}$ & $3 \mu \mathrm{m}$ & $\begin{array}{l}\text { Resonant } \\
\text { frequency }\end{array}$ & $8640.5 \mathrm{~Hz}$ \\
\hline $\begin{array}{l}\text { Height from } \\
\text { contacts }\end{array}$ & $2 \mu \mathrm{m}$ & Impact velocity & $5.4 \mathrm{~cm} / \mathrm{Sec}$ \\
\hline Cantilever type & Gold & $\begin{array}{l}\text { Actuation current } \\
(\max )\end{array}$ & $4.57 \mathrm{uA}$ \\
\hline $\begin{array}{l}\text { Thickness of } \\
\text { cantilever }\end{array}$ & $5 \mu \mathrm{m}$ & Contact area & $\begin{array}{l}2 \text { contacts } \\
40 \times 50 \mu \mathrm{m}\end{array}$ \\
\hline $\begin{array}{l}\text { Holes to } \\
\text { cantilever }\end{array}$ & Yes & $\begin{array}{l}\text { Insertion loss } \\
(4 \mathrm{G})\end{array}$ & $-0.022 \mathrm{~dB}$ \\
\hline $\begin{array}{l}\text { Electrostatic } \\
\text { force }\end{array}$ & $\begin{array}{l}174 \mu \mathrm{N} \\
(\mathrm{Vs})\end{array}$ & Return loss (ON) & $-55.83 \mathrm{~dB}$ \\
\hline Contact force & $56 \mu \mathrm{N}$ & Isolation (4G) & $-20.63 \mathrm{~dB}$ \\
\hline $\begin{array}{l}\text { Inductance of } \\
\text { cantilever }\end{array}$ & $14 \mathrm{pH}$ & $\begin{array}{l}\text { Return loss } \\
\text { (OFF) }\end{array}$ & $-0.045 \mathrm{~dB}$ \\
\hline $\begin{array}{l}\text { Capacitance } \\
(\mathrm{OFF})\end{array}$ & $2 \mathrm{x} 8.15 \mathrm{fF}$ & SNR (Hot)_ON & 78.9dB_ON \\
\hline $\begin{array}{l}\text { Switch } \\
\text { resistance }(\mathrm{ON})\end{array}$ & $\begin{array}{l}0.35 \Omega / \text { per } \\
\operatorname{contact}(\mathrm{Vs})\end{array}$ & SNR (Hot)_OFF & 71.9dB_OFF \\
\hline
\end{tabular}

\section{TABLE II}

FULL PROPERTIES OF THE TAILORED ACTUATION PULSE

\begin{tabular}{|l|l|l|}
\hline $\mathbf{a} / \mathbf{a}$ & Time & Voltage \\
\hline 1 & $0 \mu \mathrm{s}$ & $0 \mathrm{~V}$ \\
\hline 2 & $2 \mu \mathrm{s}$ & $42 \mathrm{~V}$ \\
\hline 3 & $10 \mu \mathrm{s}$ & $42 \mathrm{~V}$ \\
\hline 4 & $12 \mu \mathrm{s}$ & $0 \mathrm{~V}$ \\
\hline 5 & $24 \mu \mathrm{s}$ & $0 \mathrm{~V}$ \\
\hline 6 & $26 \mu \mathrm{s}$ & $42 \mathrm{~V}$ \\
\hline 7 & $150 \mu \mathrm{s}$ & $42 \mathrm{~V}$ \\
\hline 8 & $152 \mu \mathrm{s}$ & $0 \mathrm{~V}$ \\
\hline 9 & $156 \mu \mathrm{s}$ & $0 \mathrm{~V}$ \\
\hline 10 & $158 \mu \mathrm{s}$ & $42 \mathrm{~V}$ \\
\hline 11 & $168 \mu \mathrm{s}$ & $42 \mathrm{~V}$ \\
\hline 12 & $170 \mu \mathrm{s}$ & $0 \mathrm{~V}$ \\
\hline
\end{tabular}

\section{Conclusions and future work}

The analysis, design and simulation of a novel all metal in line series ohmic RF MEMS switch has been presented. The new design is intended to be used in microwave applications. The simplicity of the new switch due to the design technique and materials used (all metal $\mathrm{Au}$ 
design with no insulator layers) assures high fabrication yield keeping the manufacturing cost relatively low. Besides, high enough fabrication tolerances are allowed due to the wide range of actuation voltage that can be used to control the switch.

The s-shaped deformation of the cantilever adds enough restoring force to the switch in order to avoid stiction phenomena and wipes the contact area eliminating the contamination layer. In addition to that, the non-uniform shape of the design and the distributed actuation force allow easy switching control and lower actuation voltage, comparing with a uniform shaped cantilever [12], ensuring the effectiveness of the switch. The large contact surface in conjunction with the high restoring force assures good contact conditions, linearity and relatively high power operation increasing the reliability of the switch.

The electromechanical and electromagnetic simulation of the design presented significant results for the insertion loss in the ON state, the isolation in the OFF state, the required pulldown voltage, the switching time, the conductance and capacitance in the ON and OFF states, respectively. The above characteristics make the presented RF MEMS switch suitable for many microwave applications.

This research work is still on-going as concerns the control of the ohmic switch, which is being further investigated via statistical (Taguchi) optimization routines to achieve even lower impact velocity, elimination of the bouncing and settling time phenomena, while maintaining significant overall performance.

The proposed RF MEMS switch is being planned to get fabricated soon and it is anticipated that a full comparison in between theoretical and practical results will be presented in the near future.

\section{References}

[1] McKillop, J., 2007. RF MEMS: Ready for Prime Time. Microwave journal, 50 (2), pp.24.

[2] Rebeiz, G.M., 2003. RF MEMS: Theory, Design, and Technology. John Wiley \& Sons.

[3] De Los Santos, H.J., 2002. RF MEMS Circuit Design for Wireless Communications. Artech House.

[4] Coventorware, Build 2008.002.2847, Coventor, Inc. Available at: http://www.coventor.com [Accessed 10 June 2010].

[5] Newman, H.S., Ebel, J.L., Judy, D., Maciel, J., 2008. Lifetime Measurements on a HighReliability RF-MEMS Contact Switch. IEEE microwave and wireless components letters, 18 (2), pp.100-102.

[6] Tan, S.G., McErlean, E.P., Hong, J.S., Cui, Z., Wang, L., Greed, R.B., Voyce, D.C., 2005. Electromechanical Modelling of High Power RF-MEMS Switches with Ohmic Contact. In: Heriot-Watt University, European Microwave Conference. Edinburgh, UK 4-6 October 2005.

[7] Hyman, D., Mehregany, M., 1999. Contact Physics of Gold Microcontacts for MEMS Switches. IEEE Trans. Components and Packaging technologies, 22 (3), pp. 357-364.

[8] Mercado, L.L., Kuo, S., Lee, T.T., Liu, L., 2004. Mechanics-Based Solutions to RF MEMS Switch Stiction Problem. IEEE Trans. Components and Packaging technologies, 27 (3), pp. 560-567.

[9] Carton, A., Christodoulou, C.G., Dyck, C., Nordquist, C., 2006. Investigating the Impact of Carbon Contamination on RF MEMS Reliability. IEEE antennas and propagation society International Symposium, pp.193-196.

[10] Yu, A.B., Liu, A.Q., Zhang, Q.X., Hosseini, H.M., 2006. Effects of surface roughness on electromagnetic characteristics of capacitive switches. Journal of Micromech Microengineering, 16, pp.2157-2166.

[11] Ou K-S et al. (2008). A command shaping approach to enhance the dynamic performance. Mechatronics.

[12] Spasos, M., Charalampidis, N., Mallios, N., Kampitaki, D., Tsiakmakis, K., Tsivos Soel, P., Nilavalan, R., 2009. On the Design of an Ohmic RF MEMS Switch for Reconfigurable Microstrip Antenna Applications. WSEAS Transactions on Communications, 8 (1), pp.153-161. 